\title{
The role of androgens in the trade-off between territorial and parental behavior in the Azorean rock-pool blenny, Parablennius parvicornis
}

\author{
A.F.H. Ros ${ }^{\mathrm{a}, *}$, R. Bruintjes ${ }^{\text {a }}$, R.S. Santos ${ }^{\mathrm{b}}$, A.V.M. Canario ${ }^{\mathrm{c}}$, R.F. Oliveira ${ }^{\mathrm{a}}$ \\ ${ }^{a}$ Unidade de Investigação em Eco- Etologia, Instituto Superior de Psicologia Aplicada, 1149-041 Lisbon, Portugal \\ ${ }^{\mathrm{b}}$ Departamento de Oceanografia e Pescas, Universidade dos Açores, PT-9901 862 Horta, Portugal \\ ${ }^{\mathrm{c}}$ Centro de Ciências do Mar, Universidade do Algarve, Campus de Gambelas, 8005-139 Faro, Portugal
}

Received 4 August 2003; revised 8 January 2004; accepted 27 April 2004

Available online 28 July 2004

\begin{abstract}
Androgen hormones have been shown to facilitate competitive ability in courtship and territorial behavior, while suppressing paternal behavior. The rock-pool blenny, Parablennius parvicornis, provides an excellent model to study the proximate regulation of such a trade-off between territorial and parental behavior, because nest-holder males of this species display these behaviors simultaneously. A field study was carried out in which territorial nest holder males were either treated with long-lasting implants filled with 11-ketotestosterone (11-KT) or with control implants. Males treated with 11-KT showed a higher frequency of aggressive behavior, were more responsive to aggressive challenges, and were more persistent in aggressive behavior than control males. In addition, territories were larger in males treated with 11KT than in controls. We found evidence for incompatibility between defense of a large territory and high levels of parental behavior. However, contrary to expectation, 11-KT did not suppress parental behavior. We suggest that trade-offs between territorial and parental behavior may not be regulated by androgen hormones but may result from a time constraint in the individual's activity budget.

(C) 2004 Elsevier Inc. All rights reserved.
\end{abstract}

Keywords: 11-ketotestosterone; Silastic implants; Parablennius parvicornis; Aggression; Responsiveness; Territorial behavior; Territory size; Parental care; Trade-off; Azorean rock-pool blenny

\section{Introduction}

Androgen levels of males are thought to be adjusted to the social environment the animal is living in and have been proposed to promote the success in aggressive competition (Oliveira et al., 2001d; Wingfield et al., 1990). Studies that were carried out to test this hypothesis by increasing levels of androgens experimentally, found an increase in malemale competition, the territory size, and the number of extra-pair copulations (e.g., Ketterson et al., 1996). Although these effects are likely to enhance fitness, not all male individuals of a particular population raise their androgen levels to the physiological maximum during the reproductive season. Therefore, it has been proposed that high levels of testosterone are costly to maintain. Folstad

\footnotetext{
* Corresponding author. Unidade de Investigação em Eco- Etologia, Instituto Superior de Psicologia Aplicada, Rua Jardim do Tabaco 34, 1149041 Lisbon, Portugal. Fax: +351-218860954.

E-mail address: aros@ispa.pt (A.F.H. Ros).
}

and Karter (1992) suggested that only animals of good quality might be able to maintain high levels of androgens since chronic allocation of resources towards androgenmediated aggressive behavior will compromise other traits, like immunocompetence. Otherwise, Wingfield et al. (1990) proposed that androgens suppress parental care, which will constrain the expression of high levels of androgens during the breeding season in species in which males provide parental care.

Many vertebrate taxa show a negative relationship between levels of testosterone and paternal effort (e.g., Ziegler, 2000; but see Trainor and Marler, 2001). In avian species, polygynous males maintain high levels of testosterone throughout the breeding season and typically show little parental care. In monogamous parental males, levels of testosterone are high during territory establishment and mate choice but decrease at the start of the period of parental care (Wingfield et al., 1990). Likewise, in parental males of several teleost species, 11-ketotestoterone (11-KT) decreases from the mating to the parental phase (Oliveira et al., 2002). 
The goal of this study was to test the effect of androgens on aggression and parental care in the Azorean rock pool blenny, Parablennius parvicornis, a teleost that shows alternative reproductive tactics (Santos et al., 1996). Nestholder males have overlapping courtship, parental and territorial behaviors, and are therefore particularly appropriate to study the interrelation between androgens, territorial behavior and parental behavior. Oliveira et al. (2001b) showed in a natural population that parental males have higher levels of 11-KT than nonparental satellite males. Furthermore, within males of the bourgeois tactic, 11-KT levels did not differ between nonparental and parental males. Although these data show that in nest-holder males hormonal levels are relatively high, 11-KT levels showed a negative correlation with egg fanning, which is the main male parental behavior. This suggests that $11-\mathrm{KT}$ is modulating a trade-off between parental care and territorial behavior. To investigate the underlying mechanism of this trade-off, nest holder males of the rock-pool blenny were treated in the field with slow-release 11-KT implants and compared to non-hormone-treated males in respect to their territorial and parental behaviors, and in their attractiveness to females.

\section{Materials and methods}

\section{Study site and experimental procedure}

The field study was conducted from May to the end of July 2002 in intertidal rock pools on a flat basaltic platform at Feteira on the south coast of Faial Island, Azores $\left(38^{\circ} 31^{\prime} \mathrm{N} ; 28^{\circ} 27^{\prime} \mathrm{W}\right.$; for a description of the area, see Santos and Barreiros, 1993).

During an initial survey, visible male territories were mapped to select the best sites for behavioral observations and hormonal manipulation. To facilitate identification, nest-holder males were hand-netted, tagged in the dorsal muscle close to the dorsal fin with a unique combination of three colored beads $(1 \times 1.5 \mathrm{~mm}$, attached to fishing line, $\varnothing=0.3 \mathrm{~mm}$ ), and were returned to the place they were caught. Nests of captured males were guarded during the procedures to protect the eggs from predation.

Thirty-one nest-holder males were randomly assigned to experimental groups. Sixteen males received a silastic implant (length $=1 \mathrm{~cm}$, id $=1.47 \mathrm{~mm}$, od $=1.96 \mathrm{~mm}$ ) containing $20 \mu \mathrm{l} 11-\mathrm{KT}$ dissolved in castor oil $(5 \mu \mathrm{g} 11-$ $\mathrm{KT} / \mu \mathrm{l}$ castor oil; 11-KT group) in the intraperitoneal cavity. Another 15 nest-holder males were implanted with a silastic tube containing $10 \mu \mathrm{l}$ castor oil alone [control (C) group]. Eight males lost their nest during the first days after treatment and were left out of the analyses, resulting in an $n$ of 11 males in the C-group and of 12 males in the 11-KT group (mean \pm SEM: C: body weight: $24.3 \pm 1.9$ g; standard length: $11.5 \pm 0.3 \mathrm{~cm}$; 11-KT: body weight: $27.7 \pm 2.9 \mathrm{~g}$; standard length: $12.0 \pm 0.4 \mathrm{~cm}$; Mann-
Whitney $U$ tests: $U>49$, n.s.). The same procedure was used as described in Oliveira et al. (2001c). Fish were anesthetized with a light dose of MS222 (tricaine methanesulfonate, Sigma-Aldrich; dilution 1:10,000), and a small incision was made in the belly through which the silastic tube was inserted. The cut was closed with a drop of fast-drying veterinary glue. The procedure was conducted in the field and lasted about 2 min per fish. All fish recovered quickly after placing them in aerated water, after which they were returned to their nests. None of the fish died due to the treatment.

\section{Effectiveness of hormonal treatment}

To establish the effectiveness of the hormonal treatment, 19 nest-holder males, other than the abovementioned ones, were caught and were individually housed in large tanks $(2 \times 1 \mathrm{~m})$ at the Departamento de Oceanografia e Pescas, Universidade dos Açores. Ten males were implanted with a silastic tube (length $=1 \mathrm{~cm}$, id $=1.47 \mathrm{~mm}$, od $=1.96 \mathrm{~mm}$ ) containing $20 \mu \mathrm{l} 11-\mathrm{KT}$ dissolved in castor oil (5 $\mu \mathrm{g}$ 11$\mathrm{KT} / \mu \mathrm{l}$ castor oil), and nine males were implanted with a silastic tube containing castor oil only. In each tank, two flat boulders $(\varnothing \sim 15 \mathrm{~cm})$ were provided as shelters. Water was continuously pumped from the sea into the tanks, and the tanks were individually aerated. Fish were fed daily with minced clams.

One week after the start of the experiment, $0.3 \mathrm{ml}$ blood was drawn from the caudal vein with a 1-ml syringe (blood collection took approximately $1 \mathrm{~min}$ per male). Blood plasma was stored at $-20^{\circ} \mathrm{C}$ until processing. The free steroid fraction was extracted from the plasma using the methodology described by Scott and Vermeirssen (1994). Steroid residues were resuspended in 1-ml assay buffer and stored again at $-20^{\circ} \mathrm{C}$ until assayed for $11-\mathrm{KT}$. The radioimmunoassays and cross-reactions were described in Kime and Manning (1982). Intraassay (8.2\%) and interassay $(11.6 \%)$ variations were calculated as the coefficient of variation, respectively, of a control sample pool measured at six different points in one assay and of the same pool in six different assays.

The silastic implants with $11-\mathrm{KT}$ were effective in increasing circulating levels of $11-\mathrm{KT}$ in implanted fish (mean \pm SEM: C-group: $0.7 \pm 0.1 \mathrm{ng} / \mathrm{ml} ; 11-\mathrm{KT}$ group $8.2 \pm 2.7 \mathrm{ng} / \mathrm{ml}$; Mann-Whitney $U$ test: $U=1, P<0.001$ ). The average level of 11-KT in fish implanted with 11-KT was more than twice as high as measured in untreated nestholders at the study field site (Oliveira et al., 2001a,b). Even so, the highest value measured was still within the physiological range of males of $P$. parvicornis (R.F. Oliveira and A.V.M. Canario, unpublished data).

\section{Behavioral observations}

Focal observations of nest-holder males were carried out from the edge of the rock pool, during the period between 
$2 \mathrm{~h}$ before low tide and $2 \mathrm{~h}$ after low tide, and between 8:30 AM to 8:45 PM. Behavioral observations were carried out by two observers and were recorded directly on check sheets. To minimize interobserver variability, we did the following: (1) before the start of the experiment, several focal observations were carried out by the two observers together on the same (marked) subjects; (2) most of the times, focal observations by the two observers were carried out in the same pool, which allowed each observer to help the other in following the subject's behavior. Focal observations lasted $20 \mathrm{~min}$, and we collected, on average, four observations per focal animal over a period of 3 weeks.

To address the question whether 11-KT treatment modulates a trade-off between territorial and parental behavior, we recorded the following behavioral variables:

(I) Territorial behavior: (a) aggression: bites and chases directed towards an intruder on the territory. In case aggression was carried out by the subject, we recorded whether the frequency aggression was directed towards a conspecific intruder: "intraspecific aggression," or towards a member of a different species: "interspecific aggression." Furthermore, in case of "intraspecific aggression," we estimated the distance (averaged per observation) between the approaching intruder and the nest of the subject, at the time the subject responded aggressively, noted as "response distance," and the distance (maximum per observation) from the nest of the subject to where the intruder was chased by the subject, noted as "chase distance"; (b) excursion: the subject swims away from his nests, explores, and returns (in the absence of an apparent intruder). We recorded the frequency at which this behavior was carried out by the subject and the distance (averaged per observation) from the nest of the subject to where the subject went exploring.

(II) Sexual behavior: the frequency of the courtship acts quivering and circling, which are performed in the presence of a female in or close to the nest of the subject. As measurement for male attractiveness was recorded: (a) the number of females entering the nest of the subject, and (b) sexual behavior of the female in or close to the nest (i.e., laying sideways, thereby "presenting" the belly to the subject and quivering movements next to the subject).

(III) Parental behavior: the percentage of time the subject was carrying out egg fanning. Since, males of $P$. parvicornis brood in small crevices, which are often deep and uneasy to access, we were not able to check whether fanning behavior was associated with the number of developmental stage of eggs in the nest. Males that possessed more exposed nests all had eggs, but were seldom fanning.

(IV) Other behaviors that are not directly related to territorial and sexual behavior: the frequency of nest cleaning and of foraging by the subject. Behavioral categories were defined according to the ethogram provided by Santos and Barreiros (1993).

\section{Data analysis}

Observational data per animal was pooled and tested for normality using the Kolgomorov-Smirnov test. Since the distributions were significantly deviating from the normal distribution (all $P$ values $<0.05$ ), we used nonparametric statistics. Independent samples were tested by means of Mann-Whitney $U$ Test. Relationships between variables were tested with Spearman rank correlation. Using Fisher exact test, $2 \times 2$ tables were tested.

To estimate the readiness of the subject to defend the territory, we analyzed the variable "response distance." Territorial size was estimated by averaging the following variables: "response distance," "chase distance," and "excursion distance." These three variables integrate different ways in which the nest-holder holds an area in front of the nest free of conspecifics.

Since most males fanned on the edge of their nest, the occurrence of fanning could be reliably recorded. Still seven males (11-KT group $n=2$, C-group $n=5$ ) were never seen fanning, and we could not rule out that fanning in these males occurred deeper in the nest where it was impossible to observe them. Therefore, for the analyses of androgen effects on parental behavior, we only selected the nestholder males in which fanning was observed. During our initial survey of the area, we also marked floater males to follow their behavior in the pool. These males were not implanted. Some of them established territories in the areas where we were observing treated males. In case the behavior of these males was well visible, we decided to observe them, resulting in four well-documented males that showed fanning behavior. To increase the sample size of the C-group, data of these males were added, resulting in an $n$ of 10 males for both groups (i.e., C and 11-KT). Power analyses were carried out to assess the probability of type II errors.

All analyses were performed using the SPSS 11.0 statistical package (SPSS Inc., Chicago, USA). All statistics used an alpha of 0.05 (two-tailed).

\section{Results}

\section{Effects of 11-KT on social behavior and territoriality}

11-KT treatment increased the frequency of intraspecific aggression and of excursions (Fig. 1; Mann-Whitney $U$ tests: intraspecific aggression, $U=26.5, P<0.05$, excursions, $U=24.5, P<0.01$ ), while no effect was found on interspecific aggression (Fig. 1). Treatment with 11-KT did not affect sexual behavior of the nest-holders (Fig. 1) and had no effect neither on the frequency of sexual behavior received from females, nor on the number of females that 


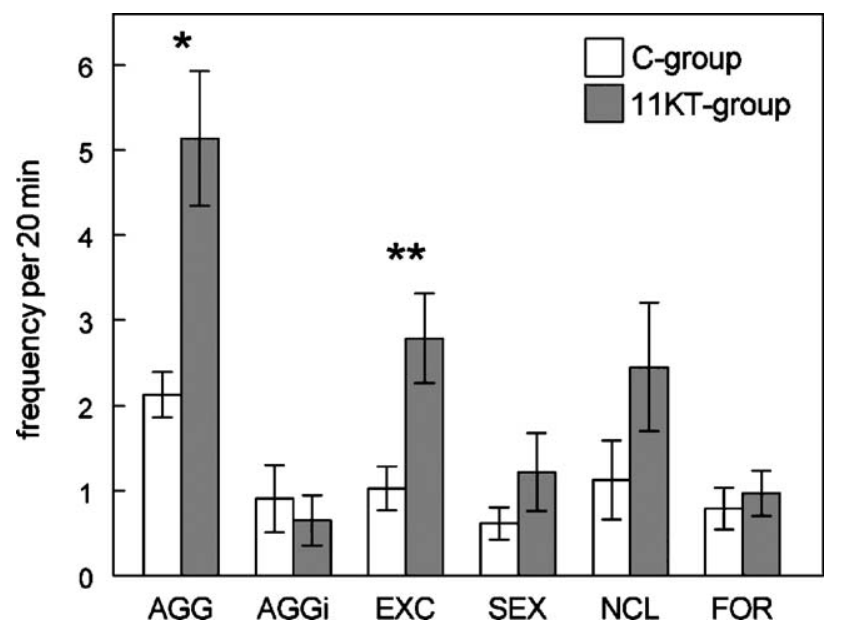

Fig. 1. The effect of experimental treatment with silastic implants containing $11-\mathrm{KT}$ in castor oil or containing castor oil only on the occurrence of intraspecific aggression (AGG), interspecific aggression (AGGi), explorative excursions (EXC), sexual behavior (SEX), nest-cleaning behavior (NCL), and foraging (FOR). C-group: $n=11 ; 11-\mathrm{KT}$ : group $n=12$. Means $\pm \mathrm{SEM}$ are given.

entered the nest of the focal male. Furthermore, no effect of the treatment was found on behaviors that may be performed outside the social context, like nest-cleaning behavior and foraging (Fig. 1).

Nest-holders treated with 11-KT made explorative excursions farther away from the nest than control nest-holders (Fig. 2, Mann-Whitney $U$ test: $U=29.5, P<0.05$ ). Hormonal treatment significantly increased the responsiveness to conspecific intruders, since males treated with 11KT responded at longer distances at approaching conspecifics (Fig. 2, Mann-Whitney $U$ test: $U=32, P<0.05$ ) and chased them over longer distances than males of the control group (Fig. 2, Mann-Whitney $U$ test: $U=34, P<0.05$ ).

Response distance was positively correlated with both excursion distance and chase distance (Spearman rank correlation: excursion distance, $R=0.58, n=22, P<$ 0.01; chase distance, $R=0.70, n=23, P<0.001)$. Therefore, to estimate territory size, we pooled the distance subjects swam away from the nest during territorial interactions (response and chase distance) and during excursions. This analyses showed that treatment with $11-\mathrm{KT}$ caused a $60 \%$ increase in territory size $(\mathrm{C}: n=10,16.7 \pm 2.4 \mathrm{~cm}, 11-$ KT: $n=12,26.9 \pm 2.2 \mathrm{~cm}$, Mann-Whitney $U$ test: $U=20$, $P<0.01)$.

\section{Effects of 11-KT on parental behavior}

No significant difference was found in fanning between the 11-KT group and the C-group (C: $18.0 \pm 6.0 \%$; 11-KT: $12.4 \pm 4.6 \%$; mean \pm SEM). Power analyses showed that, with a power of 0.8 , a suppression of fanning of $65 \%$ or more might be excluded. This implies that elevated levels of 11-KT were not incompatible with the normal expression of parental behavior in P. parvicornis.
To further examine the effect of 11-KT on parental behavior, we selected males that were showing fanning during the first observation week and calculated the percentage of individuals that continued to fan in the following weeks. Again, no effect of hormonal treatment on fanning behavior was found (C-group, $n=7,43 \%$; 11-KT group, $n=7,57 \%$ ).

To check for the expected trade-off between aggressive behavior and fanning, regression analyses showed a negative correlation between fanning behavior and territory size but not with intraspecific aggression (Spearman rank correlation, territory size: $R=-0.54, n=20, P<0.05$; intraspecific aggression: $R=-0.28, n=20$, n.s.).

\section{Discussion}

The aim of our experiment was to investigate whether 11-KT regulates the trade-off between territorial and parental behaviors in teleost species that show these behaviors simultaneously. Based on the challenge hypothesis, we expected that androgens would suppress parental behavior (Wingfield et al., 1990; for a recent review, see Hirschenhauser et al., 2003). In a field study, nest-holder males of the Azorean rock-pool blenny, $P$. parvicornis, were treated with long-lasting implants of 11-KT, which, in agreement with the general trend in teleost fishes (e.g., see Borg, 1994; Liley and Stacey, 1983; Nelson, 1999), caused an increase in the frequency of intraspecific aggressive behavior and in the size of the territory. We found that nest-holder males with high levels of egg fanning, the primary parental care in teleost fish, had smaller territories than males that showed less egg fanning. However, contrary to expectation, treat-

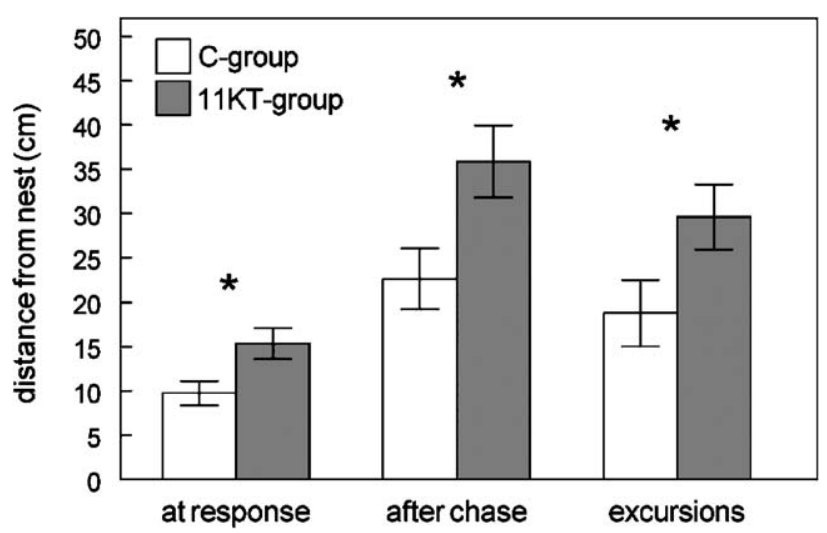

Fig. 2. The effect of experimental treatment with silastic implants containing 11-KT in castor oil or containing castor oil only on territorial behavior; at response: the distance between an approaching intruder and the nest at the time the focal male responded aggressively; after chase: the maximum distance from the nest at which a conspecific was followed during an aggressive chase; excursions: the average distance from the nest at which a male was exploring during an excursion. C-group: response and chase distance: $n=11$, excursion distance: $n=10 ; 11-\mathrm{KT}$ group: $n=12$. Means $\pm \mathrm{SEM}$ are given. 
ment of nest-holders with 11-KT did not suppress egg fanning.

Recently, Oliveira et al. (2002) reviewed the available data for teleosts representing six different families in which males provide care for the offspring. In accordance with the proposed trade-off between high androgen levels and parental care, in all these species, endogenous levels of 11-KT were higher in males sampled in the mating phase than in the parental phase. On the other hand, evidence is accumulating from experimental studies in teleosts that suppression of parental care is not caused by a direct effect of androgens. In male blue gill, Lepomis macrochirus, although plasma levels of 11-KT decrease when males start caring for eggs (Kindler et al., 1989), no influence was found of exogenous 11-KT on male parental behavior (Kindler et al., 1991). Also, in the three-spined stickleback, Gasterosteus aculeatus, levels of 11-KT decrease in males that spawn and care for eggs, but egg-fanning behavior was not different between castrated males, castrated males treated with $11-\mathrm{KT}$, and sham-operated males (Páll et al., 2002b). In these species and in P. parvicornis, the social system is promiscuous and only males take care of the brood. Similarly, in a Neotropical frog (Eleutherodactylus coqui) in which males carry eggs on their back, although plasma androgen levels in brooding males were significantly lower than in nonbrooding males (Townsend and Moger, 1987), no influence of exogenous testosterone on male parental behavior was found (Townsend et al., 1991).

Comparable to lower vertebrates, males of some mammalian species may share parental care with sexual and aggressive activities, and even a positive association between parental care and androgen levels has been found in such species (Trainor and Marler, 2001). In contrast, in most of the studied avian species in which males share parental care with a female, parental care was found to be suppressed when these males were treated with testosterone (De Ridder et al., 2000; Hegner and Wingfield, 1987; Hunt et al., 1999; Ketterson and Nolan, 1992; McDonald et al., 2001; Silverin, 1980; Stoehr and Hill, 2000). In many of the studied bird species, the fitness consequences of spending less effort in the current offspring by increased polygamous behavior are reduced because the partner may partly compensate for the decrease in paternal care (e.g., see Hunt et al., 1999; Ketterson and Nolan, 1992; Kokita, 2002; Slagsvold and Lifjeld, 1994; Stoehr and Hill, 2000, but see De Ridder et al., 2000 and McDonald et al., 2001). Under such consequences, selection for androgen-regulated suppression of parental care might be beneficial because it frees up time for the male to engage in polygamous behavior.

However, also in birds, the mechanism might be more flexible than initially thought. Recently, it was shown in the great tit (Parus major) that experimentally elevated levels of testosterone did not decrease paternal feeding rate, while it did enhance song activity (van Duyse et al., 2000, 2002). The latter study was carried out in a population in which opportunities for extra-pair copulations and further breeding attempts were low, and the authors therefore suggested that when male participation in parental care is more important, high androgen levels should be less likely to suppress paternal care (van Duyse et al., 2000). Alternatively, it might be argued that, in the absence of receptive females, these males did not spend much time in extra-pair activities and therefore did not compromise their parental care behavior. In such an interpretation, testosterone exerts its effect on parental behavior indirectly via constraints in the time budget of the male.

Our data are in agreement with other studies on lower vertebrates. Based on correlative data, a negative relationship between 11-KT and parental behavior was expected (Oliveira et al., 2001b). However, such a relationship was not found to be causal, since experimentally increasing the plasma levels of the hormone had no effect on parental behavior. Still, one may ask why, in other teleosts, levels of androgens are found to decrease from the preparental phase to the parental phase (see Oliveira et al., 2002). The decrease of androgen levels during brooding is most probably a result of physiological and behavioral contributions. The social environment the animal is living in plays an important role in explaining the variation in androgen levels (Wingfield et al., 1990). In seasonally reproducing animals, the social environment changes importantly in the course of the reproductive season. Androgen levels increase when male-male competition is most intense during the period males acquire breeding territories and compete for females at the start of the season (e.g., see Wingfield et al., 1990). Later in the season when breeding males have established territories and start caring for eggs, the intensity of malemale competition will decrease, which may explain why androgen levels decrease in parental males. Furthermore, it has been suggested that in the mouth-brooding blackchinned tilapia, Sarotherodon melanotheron, the presence of eggs decreases androgen levels possibly through a chemical signal released from the eggs (Specker and Kishida, 2000). Similarly, in the three-spined stickleback, levels of 11-KT have been shown to correlate with the development off the eggs in the nest (Páll et al., 2002a). The latter data suggest a regulated suppression in the levels of $11-\mathrm{KT}$ in males that have eggs, implying selection mechanisms acting against high levels of 11-KT in such males.

No effect of 11-KT was detected on any of the nonterritorial behaviors we recorded, that is, nest cleaning, foraging behavior, and courtship behaviors. Also, in an earlier field study with $P$. parvicornis, no correlation was found between endogenous levels of 11-KT and courtship behaviors in nest-holder males (Oliveira et al., 2001b). Furthermore, the effect of $11-\mathrm{KT}$ on territorial behavior was found to be specific for intraspecific aggression. These results indicate that androgens primarily affected neural mechanisms controlling aggressive behavior in a territorial context.

Nest-holder males of the 11-KT group were attacking conspecifics at a farther distance from the nest, chased 
conspecifics farther away from the nest, and during excursions from the nest that were initiated in the absence of agonistic stimuli, they explored areas farther away from the nest than males of the C-group. This indicates that males treated with 11-KT had increased their territory size in comparison with control males, which is in agreement with studies in avian species showing that males with experimentally increased levels of testosterone during the reproductive season respond more rapidly with aggressive behavior to territorial challenges than control males (e.g., white crowned sparrow, Zonotrichia leucophrys, Moore, 1984; dark-eyed junco, Junco hyemalis, Ketterson and Nolan, 1992; great tit, Parus major, van Duyse et al., 2002; black-headed gull, Larus ridibundus, Ros et al., 2002) and increase their territory size (e.g., dark-eyed junco, Junco hyemalis, Chandler et al., 1994; red grouse, Lagopus lagopus, Moss et al., 1994). The farther distance from the nest at which conspecifics were attacked in androgen-treated males is also in agreement with the hypothesis that androgens increase the responsiveness to social stimuli (e.g., Wingfield, 1994).

In a laboratory experiment, Oliveira et al. (2001c) showed that $P$. parvicornis satellite males treated with 11KT or methyl-testosterone developed secondary sexual characters characteristic of bourgeois males (Oliveira et al., 2001c). However, in contrast with our results on nestholder males in the field, androgen treatment decreased aggressive behavior in these satellite males. This difference may indicate differential mechanisms of action of androgens on aggressive behavior between the two male types, since satellite males are smaller and younger than nest-holder males (Santos et al., 1995). In fact, although satellite males show high levels of aggression, they have relative low levels of androgens (Oliveira et al., 2001b,c). Thus, aggression in these younger animals might be less dependent on high circulating levels of androgens (see Ros et al., 2001). Alternatively, this difference can be due to the fact that the satellites were tested in the laboratory while the effect of 11-KT on nest-holder behavior was assessed in the field. As the present study indicates, androgens might enhance the responsiveness to an agonistic challenge, and in general, agonistic interactions in the field are asymmetric (in respect to body size and territory ownership) and of short duration. On the other hand, in the mirror image test used in the laboratory study to elicit aggression (Oliveira et al., 2001c), the subject is exposed to a symmetric opponent, and the endurance in fighting is measured, which is a different aspect of aggressive behavior and might have a different causation. Further studies are needed to disentangle these two possibilities.

In conclusion, we showed that androgen treatment increased territorial behavior but, contrary to expectation, did not suppress parental behavior in P. parvicornis. We propose that in teleost species in which males take care of the brood alone, the demand to spend time in parental care constrains the performance of other social activities. The negative relationship between androgen levels and parental care found in earlier studies might have been a consequence of lower exposure to male-male competition in parental males.

\section{Acknowledgments}

We are very grateful to Elsa Couto for running the radioimmunoassay. During this study, AFHR was being supported by a postdoctoral fellowship from the Portuguese Foundation for Science and Technology (FCT) (SFRH / BPD / 7143 / 2001). RFO's and AFHR's research is supported by FCT's Plurianual Program (R and D Unit 331/ 94). The procedures used in this study comply with the "Principles of animal care," publication No. 86-23, revised 1985, of the National Institutes of Health, USA, and with the current laws of Portugal. The "Stichting Groninger Universiteitsfonds" and the "Marco Polo Fonds" of the University of Groningen, the Netherlands, funded travels of RB between the Netherlands, Azores, and Portugal.

\section{References}

Borg, B., 1994. Androgens in teleost fishes. Comp. Biochem. Physiol., C: Comp. Pharmacol. 109, 219-245.

Chandler, C.R., Ketterson, E.D., Nolan Jr., V., Ziegenfus, C., 1994. Effects of testosterone on spatial activity in free-ranging male dark-eyed juncos, Junco hyemalis. Anim. Behav. 47, 1445-1455.

De Ridder, E., Pinxten, R., Eens, M., 2000. Experimental evidence of a testosterone-induced shift from paternal to mating behaviour in a facultatively polygynous songbird. Behav. Ecol. Sociobiol. 49, 24-30.

Folstad, I., Karter, A., 1992. Parasites, bright males, and the immunocompetence handicap. Am. Nat. 139, 603-622.

Hegner, R.E., Wingfield, J.C., 1987. Effects of experimental manipulation of testosterone levels on parental investment and breeding success in male house sparrows. Auk 104, 462-469.

Hirschenhauser, K., Winkler, H., Oliveira, R.F., 2003. Comparative analyses of male androgen responsiveness to social environment in birds: the effects of mating system and paternal incubation. Horm. Behav. 43, $508-519$.

Hunt, T.P., Hahn, J.C., Wingfield, J.C., 1999. Endocrine influences on parental care during a short breeding season: testosterone and male parental care in Lapland longspurs (Calcarius lapponicus). Behav. Ecol. Sociobiol. 45, 360-369.

Ketterson, E.D., Nolan Jr., V. 1992. Testosterone and life histories: an integrative approach. Am. Nat. 140, S33-S62.

Ketterson, E.D., Nolan Jr., V., Cawthorn, M.J., Parker, P.G., Ziegenfus, C., 1996. Phenotypic engineering: using hormones to explore the mechanistic and functional bases of phenotypic variation in nature. Ibis 138 , $70-86$.

Kime, D.E., Manning, N.J., 1982. Seasonal patterns of free and conjugated androgens in the brown trout Salmo trutta. Gen. Comp. Endocrinol. 48, $222-231$.

Kindler, P.M., Phillipp, D.P., Gross, M.R., Bahr, J.M., 1989. Serum 11-ketotestosterone and testosterone concentrations associated with reproduction in male bluegill (Lepomis macrochirus: Centrarchidae). Gen. Comp. Endocrinol. 75, 446-453.

Kindler, P.M., Bahr, J.M., Philipp, D.P., 1991. The effects of exogenous 11-ketotestosterone, testosterone, and cyproterone acetate on prespawning and parental care behaviors of male bluegill. Horm. Behav. 25, $410-423$. 
Kokita, T., 2002. The role of female behavior in maintaining monogamy of a coral-reef filefish. Ethology 108, 157-168.

Liley, N.R., Stacey, N.E., 1983. Hormones, pheromones, and reproductive behavior in fish. In: Hoar, W.S., Randall, D.J., Donaldson, E.M. (Eds.), Fish Physiology. Reprod.: Behav. Fertil. Control, vol. 9B. Academic Press, New York, pp. 1-63.

McDonald, P.G., Buttemer, W.A., Astheimer, L.B., 2001. The influence of testosterone on territorial defence and parental behavior in male freeliving rufous whistlers, Pachycephala rufiventris. Horm. Behav. 39, $185-194$.

Moore, M.C., 1984. Changes in territorial defense produced by changes in circulating levels of testosterone: a possible hormonal basis for mateguarding behavior in white-crowned sparrows. Behaviour 88, 215-226.

Moss, R., Parr, R., Lambin, X., 1994. Effects of testosterone on breeding density, breeding success and survival of red grouse. Proc. R. Soc. London, Ser. B 258, 175-180.

Nelson, R.J., 1999. An Introduction to Behavioural Endocrinology. Sinauer Assoc., Sunderland, MA.

Oliveira, R.F., Canario, A.V.M., Grober, M.S., 2001a. Male sexual polymorphism, alternative reproductive tactics, and androgens in combtooth blennies (Pisces: Blenniidae). Horm. Behav. 40, 266-275.

Oliveira, R.F., Canario, A.V.M., Grober, M.S., Santos, R.S., 2001b. Endocrine correlates of male polymorphism and alternative reproductive tactics in the Azorean rock-pool blenny, Parablennius sanguinolentus parvicornis. Gen. Comp. Endocrinol. 121, 278-288.

Oliveira, R.F., Carneiro, L.A., Canario, A.V.M., Grober, M.S., 2001c. Effects of androgens on social behavior and morphology of alternative reproductive males of the Azorean rock-pool blenny. Horm. Behav. 39, $157-166$.

Oliveira, R.F., Lopes, M., Carneiro, L.A., Canario, A.V.M., 2001d. Watching fights raises fish hormone levels. Nature 409, 475.

Oliveira, R.F., Hirschenhauser, K., Carneiro, L.A., Canario, A.V.M., 2002. Social modulation of androgen levels in male teleost fish. Comp. Biochem. Physiol., Part B: Biochem. Mol. Biol. 132, 203-215.

Páll, M.K., Mayer, I., Borg, B., 2002a. Androgen and behavior in the male three-spined stickleback, Gasterosteus aculeatus: I. Changes in 11-ketotestosterone levels during the nesting cycle. Horm. Behav. 41, 377-383.

Páll, M.K., Mayer, I., Borg, B., 2002b. Androgen and behavior in the male three-spined stickleback, Gasterosteus aculeatus: II. Castration and 11ketoandostenedione effects on courtship and parental care during the nesting cycle. Horm. Behav. 42, 337-344.

Ros, A.F.H., Hirschenhauser, K., Oliveira, R.F., 2001. The interaction between organizational and activational effects of testosterone in the control of early aggression in birds: a comment on Sasvári, Hegyi and Péczely. Ethology 107, 1-3.

Ros, A.F.H., Dieleman, S.J., Groothuis, T.G.G., 2002. Social stimuli, testosterone, and aggression in gull chicks: support for the challenge hypothesis. Horm. Behav. 41, 334-342.
Santos, R.S., Barreiros, J.P., 1993. The ethogram of Parablennius sanguinolentus parvicornis (Valenciennes in Cuvier and Valenciennes, 1836) (Pisces: Blenniidae) of the Azores. Arquipél., Life Mar. Sci. 11A, 73-90.

Santos, R.S., Nash, R.D.M., Hawkins, S.J., 1995. Age, growth and sex ratio of the Azorean rock-pool blenny, Parablennius sanguinolentus parvicornis. J. Mar. Biol. Assoc. U.K. 75, 751-754.

Santos, R.S., Hawkins, S.J., Nash, R.D.M., 1996. Reproductive phenology of the Azorean rock pool blenny, a fish with alternative mating tactics. J. Fish Biol. 48, 842-858.

Scott, A.P., Vermeirssen, E.L.M., 1994. Production of conjugated steroids by teleost gonads and their role as pheromones. In: Davey, K.G., Peter, R.E., Tobe, S.S. (Eds.), Perspectives in Comparative Endocrinology. National Research Council of Canada, Ottawa, pp. 645-654.

Silverin, B., 1980. Effects of long-acting testosterone treatment on freeliving pied flycatchers, Ficedula hypoleuca, during the breeding period. Anim. Behav. 28, 906-912.

Slagsvold, T., Lifjeld, J.T., 1994. Polygyny in birds-The role of competition between females for male parental care. Am. Nat. 143, 59-94.

Specker, J.L., Kishida, M., 2000. Mouthbrooding in the black-chinned tilapia, Sarotherodon melanotheron (Pisces: Cichlidae): the presence of eggs reduces androgen and estradiol levels during paternal and maternal parental behavior. Horm. Behav. 38, 44-51.

Stoehr, A.M., Hill, G.E., 2000. Testosterone and the allocation of reproductive effort in male house finches (Carpodacus mexicanus). Behav. Ecol. Sociobiol. 48, 407-411.

Townsend, D.S., Moger, W.H., 1987. Plasma androgen levels during male parental care in a tropical frog (Eleutherodactylus). Horm. Behav. 21, $93-99$.

Townsend, D.S., Palmer, B., Guillette Jr., L.J. 1991. The lack of influence of exogenous testosterone on male parental behavior in a Neotropical frog (Eleutherodactylus): a field experiment. Horm. Behav. 25, 313-322.

Trainor, B.C., Marler, C.A., 2001. Testosterone, paternal behavior, and aggression in the monogamous California mouse (Peromyscus californicus). Horm. Behav. 40, 32-42.

van Duyse, E., Pinxten, R., Eens, M., 2000. Does testosterone affect the trade-off between investment in sexual/territorial behaviour and parental care in great tits? Behaviour 137, 1503-1515.

van Duyse, E., Pinxten, R., Eens, M., 2002. Effects of testosterone of song, aggression and nestling feeding behavior in male great tits, Parus major. Horm. Behav. 41, 178-186.

Wingfield, J.C., 1994. Regulation of territorial behavior in the sedentary song sparrow, Melospiza melodia morphna. Horm. Behav. 28, 1-15.

Wingfield, J.C., Hegner, R.E., Dufty Jr., A.M., Ball, G.F. 1990. The challenge hypothesis: theoretical implications for patterns of testosterone secretion, mating systems, and breeding strategies. Am. Nat. 136, $829-846$.

Ziegler, T.E., 2000. Hormones associated with non-maternal infant care: a review of mammalian and avian studies. Folia Primatol. 71, 6-21. 